\title{
Thermo-sensitive electroactive hydrogel combined with electrical stimulation for repair of spinal cord injury
}

Wei Liu ${ }^{1,2}$, Yiqian Luo ${ }^{1}$, Cong Ning ${ }^{1}$, Wenjing Zhang ${ }^{3}$, Qingzheng Zhang ${ }^{1}$, Haifeng Zou ${ }^{2 *}$ (D) and Changfeng Fu ${ }^{{ }^{*}}$

\begin{abstract}
The strategy of using a combination of scaffold-based physical and biochemical cues to repair spinal cord injury (SCI) has shown promising results. However, integrating conductivity and neurotrophins into a scaffold that recreates the electrophysiologic and nutritional microenvironment of the spinal cord (SC) remains challenging. In this study we investigated the therapeutic potential of a soft thermo-sensitive polymer electroactive hydrogel (TPEH) loaded with nerve growth factor (NGF) combined with functional electrical stimulation (ES) for the treatment of SCl. The developed hydrogel exhibits outstanding electrical conductance upon ES, with continuous release of NGF for at least 24 days. In cultured nerve cells, TPEH loaded with NGF promoted the neuronal differentiation of neural stem cells and axonal growth, an effect that was potentiated by ES. In a rat model of SCI, TPEH combined with NGF and ES stimulated endogenous neurogenesis and improved motor function. These results indicate that the TPEH scaffold that combines ES and biochemical cues can effectively promote SC tissue repair.
\end{abstract}

Keywords: Spinal cord injury, Polyvaline, Tetraniline, Electroactive hydrogel, Electrical stimulation, Endogenous neurogenesis

\section{Introduction}

Spinal cord injury (SCI) disrupts the connection between the brain and peripheral organs, leading to sensory motor dysfunction [1]. In addition, SCI can lead to a series of secondary diseases, for example, deep vein thrombosis, muscle spasms, osteoporosis, urinary tract infections, bedsores, chronic pain, and respiratory complications, which are detrimental to the patient's daily activities and even life-threatening [1-3]. Current treatment options for SCI do not yield satisfactory results.

The endogenous bioelectric signals and neurotrophins in the spinal cord (SC) are indispensable in maintaining

\footnotetext{
*Correspondence: zouhf@jlu.edu.cn; fucf@jlu.edu.cn

${ }^{1}$ Department of Spine Surgery, The First Hospital of Jilin University, 1 Xinmin Street, Changchun 130021, People's Republic of China

${ }^{2}$ College of Chemistry, Jilin University, 2699 Qianjin Street, Changchun 130012, People's Republic of China

Full list of author information is available at the end of the article
}

the physiological activities of neurons, including proliferation, migration, differentiation, and axon growth. [4]. After SCI, the electrical signal transduction is impaired and endogenous neurotrophins are depleted, which hinders tissue repair [5]. Electrical stimulation (ES) is commonly used for the treatment of SCI; in addition to maintaining muscle strength and volume and preventing denervated muscle atrophy, ES regulates the physiologic activities of nerve cells such as proliferation, differentiation, and axon growth [6,7]. In addition, nerve growth factor (NGF) stimulates axon growth and differentiation of neural stem cells (NSCs) $[8,9]$; exogenous NGF can supplement endogenous neuronutrients during $\mathrm{SC}$ tissue repair, but multiple administrations are required because of its short half-life in vivo for $4 \mathrm{~h} \mathrm{[10].}$

An electroactive neuronutrient bridge can in theory reconnect disrupted neural pathways by continuously release nutrients and responding to external ES original author(s) and the source, provide a link to the Creative Commons licence, and indicate if changes were made. The images or other third party material in this article are included in the article's Creative Commons licence, unless indicated otherwise in a credit line to the material. If material is not included in the article's Creative Commons licence and your intended use is not permitted by statutory regulation or exceeds the permitted use, you will need to obtain permission directly from the copyright holder. To view a copy of this licence, visit http://creativecommons.org/licenses/by/4.0/. The Creative Commons Public Domain Dedication waiver (http://creativeco mmons.org/publicdomain/zero/1.0/) applies to the data made available in this article, unless otherwise stated in a credit line to the data. 
to promote endogenous neurogenesis for SCI repair. Hydrogels are an ideal candidate scaffold for this purpose because of their high water content, biocompatibility, 3-dimensional (3D) porous structure, and mechanical properties similar to $\mathrm{SC}$, which meet the requirements of nerve cell adhesion, metabolic substance exchange, and bioactive substance loading for SC regeneration $[11,12]$. Hydrogel scaffolds also have electrical conductivity and can simulate the electrophysiologic environment of nerve tissue in combination with exogenous ES. Hydrogels have been used for nerve repair through the delivery of small molecule drugs in a rat brachial plexus injury model [13].

Conductive polymers (CPs) not only have good biocompatibility but also excellent electrical conductivity that can stimulate cell adhesion, proliferation, and differentiation at the polymer-tissue interface to promote tissue growth [14]. These electrically conductive biomaterials can potentially be used to construct neural tissue engineering scaffolds [15]. Polyaniline (PANI) is a CP with excellent physical and chemical properties because of its unique conjugated structure and doping mechanism [16]. However, PANI also has several drawbacks for physiologic applications such as poor flexibility, poor degradability and processing, and low solubility, which can lead to chronic inflammation and pain [17]. Additionally, hydrogels swell under physiologic conditions and ionically or physically loaded PANI could leach out, leading to the decrease of conductivity as well as toxicity.

Poly(amino acid) have excellent properties such as biocompatibility, nontoxicity after degradation, safety, and ease of modification that make them suitable for biomedical applications [18-21]. It is possible that poly(amino acid) can be used to alleviate the shortcomings of CPs for application in neural tissue engineering.

Herein, we prepared an electroactive hydrogel based on poly(amino acid) and the electrically responsive PANI, and combined this with ES to achieve a more potent therapeutic effect in the repair of SC tissue. We grafted tetraniline (TA) onto a previously prepared poly(ethylene glycol)-co-polyvaline (mPEG-PLV) polymer to produce a thermosensitive polymer electroactive hydrogel (TPEH) that was loaded with NGF. The TPEH promoted neuronal differentiation, at the same time inhibiting astrocyte differentiation in vitro, and restored spinal circuitry and locomotor function by stimulating endogenous neurogenesis in a rat $\mathrm{SCI}$ model.

\section{Materials and methods}

\section{Materials}

1-Ethyl-3-(3-dimethylaminopropyl)-carbodiimide (EDC), mPEG $_{2000}-\mathrm{OH}$, and $N$-phenyl-1,4-phenylenediamine were purchased from Sigma-Aldrich (St. Louis, MO, USA). Triphosgene was obtained from Shanghai Duodian
Chemical Co., Ltd. (Shanghai, P. R. China). L-Valine was purchased from GL Biochem, Ltd. (Shanghai, P. R. China). $N$-hydroxysuccinimide (NHS) was purchased from Honeywell Research Chemicals (Charlotte, NC, USA). Dimethyl sulfoxide (DMSO), N,N-dimethylformamide (DMF), tetrahydrofuran (THF), toluene, methylene chloride $\left(\mathrm{CH}_{2} \mathrm{Cl}_{2}\right)$, chloroform $\left(\mathrm{CHCl}_{3}\right)$, hydrochloric acid $(\mathrm{HCl})$, and other chemicals were purchased from Beijing Chemical Industry Group Co., Ltd. (P. R. China).

\section{Synthesis and characterization of MPEG-PLV-TA copolymer mPEG-PLV copolymer}

$\mathrm{mPEG}_{2000}-\mathrm{NH}_{2}$ was prepared by terminal amination of $\mathrm{mPEG}_{2000} \mathrm{OH}$ as described in our previous work [22]. Meanwhile, L-Valine $\mathrm{N}$-carboxylicanhydride (L-Val NCA) was prepared by mixing triphosgene and $\mathrm{L}-\mathrm{Val}$ in THF solutio. mPEG-PLV copolymer was obtained from ringopening polymerization of recrystallized $\mathrm{L}-\mathrm{Val} \mathrm{NCA}$ initiated with $\mathrm{mPEG}_{2000}-\mathrm{NH}_{2}$. In brief, $\mathrm{mPEG}_{2000}-\mathrm{NH}_{2}$ was co-boiled with toluene to remove the water to obtain dry mPEG2000- $\mathrm{NH}_{2}$ was added to the DMF solution of $\mathrm{L}$-Val NCA, t. The reaction vessel was stabilized at $25^{\circ} \mathrm{C}$ through the thermostatic oil bath and stirred for 3 days. The Polymerization product was collected through sedimentation, filtration, and dialysis and freeze-dried under vacuum.

\section{Carboxyl-capped aniline tetramer (CTA)}

First, tetraaniline (TA) was synthesized as previously reported [23]. Briefly, $N$-pheny-1,4-phenylenediamine $(3.68 \mathrm{~g}, 0.02 \mathrm{~mol})$ was dissolved in a solution of acetone $(100 \mathrm{~mL}), \mathrm{HCl}(25 \mathrm{~mL})$, and water $(100 \mathrm{~mL})$. In an ice bath, ammonium persulfate (APS, $4.56 \mathrm{~g}, 0.02 \mathrm{~mol}$ ) dissolved in hydrochloric acid $(50 \mathrm{~mL}, 1 \mathrm{M})$ was added dropwise, and the reaction was continued for $3 \mathrm{~h}$ to obtain TA. Under nitrogen protection, CTA was obtained by mixing TA and succinic anhydride in $\mathrm{CH}_{2} \mathrm{Cl}_{2}$ solution $(5 \times$ the molar weight $)$ at room temperature for $5 \mathrm{~h}$, followed by extraction and filtration. Coarse products were repeatedly washed with distilled water and finally extracted with $\mathrm{CH}_{2} \mathrm{Cl}_{2}$ with a Soxhlet fat extractor to obtain a colorless CTA powder, which was dried under vacuum.

\section{mPEG-PLV-TA copolymer}

To prepare the mPEG-PLV-TA copolymer, $1.0 \mathrm{mmol}$ mPEG-PLV, $1.0 \mathrm{mmol}$ CTA, $2.0 \mathrm{mmol}$ EDC, and $2.0 \mathrm{mmol}$ NHS were dissolved in a dried glass reactor containing $10.0 \mathrm{~mL}$ of DMSO. The mixture was heated to $50{ }^{\circ} \mathrm{C}$ for $48 \mathrm{~h}$ under a nitrogen atmosphere. After the reaction, the copolymer was precipitated in ether to 
obtain the crude product. For further refinement, this was dissolved in DMSO and the solution was filtered; the filtrate was dialyzed for 7 days to remove impurities and freeze-dried for 3 days.

\section{Phase diagram and internal structure}

The sol-gel transition behavior of the copolymer in phosphate-buffered saline (PBS) ( $\mathrm{pH}$ 7.4) was determined with the test tube inversion method. Samples with concentrations ranging from 4.0 to $8.0 \mathrm{wt} \%$ were dissolved in PBS and stirred at $4{ }^{\circ} \mathrm{C}$ for $12 \mathrm{~h}$. The copolymer solution $(0.2 \mathrm{~mL})$ was decanted into a test tube with an inner diameter of $10.0 \mathrm{~mm}$ with a gradual increase in temperature. The sol-gel transition temperature was recorded if no flow was observed within $30 \mathrm{~s}$ after inverting the test tube. Each data point was the average of three measurements.

To examine the internal structure, hydrogel samples were prepared as described above and lyophilized by freezing in liquid nitrogen for $30 \mathrm{~s}$. The samples were observed by scanning electron microscopy (SEM) (model XL30; Philips, Eindhoven, The Netherlands) at an acceleration voltage of $10 \mathrm{kV}$.

\section{In vitro and in vivo hydrogel degradation}

To analyze the degradation properties of the mPEGPLV-TA hydrogel in vitro, $3.0 \mathrm{~mL}$ of PBS without or with elastase $(2.0 \mathrm{mg} / \mathrm{mL})$ was slowly added to the surface of hydrogels in cylindrical vials and the samples were placed in a $37^{\circ} \mathrm{C}$ incubator with shaking at $70 \mathrm{rpm}$. After removing the PBS every other day, the vials were weighed, and the recorded values were used to plot the degradation curve.

Wistar rats (weighing 250 g, provided by the Experimental Animal Center of Jilin University, Changchun, China) were used to evaluate gel degradation in vivo. Rats were anesthetized with $2 \%$ isoflurane in oxygen (Sevorane; Abbott Spa, Campoverde, Italy), and $0.5 \mathrm{~mL}$ of mPEG-PLV-TA PBS solution (6.0 wt\%) was injected into the dorsal subcutaneous area using a 21-gauge needle. At $1 \mathrm{~h}$ and 7, 14, and 28 days, the skin of rats was carefully cut open to expose the hydrogels, and the hydrogels and surrounding skin were photographed and collected. The skin was fixed overnight with $4 \%(w / v)$ paraformaldehyde and embedded in paraffin; the tissue blocks were cut into sections at a thickness of $4 \mu \mathrm{m}$ that were stained with hematoxylin and eosin (H\&E), and inflammation was assessed under a light microscope (model TE2000U; Nikon, Kanagawa, Japan).

\section{NGF loading and release}

The mPEG-PLV-TA hydrogel loaded with NGF was prepared by dissolving $60 \mathrm{mg}$ mPEG-PLV-TA copolymer and $10.0 \mu \mathrm{g} \mathrm{NGF}$ in $1 \mathrm{~mL}$ PBS at $4{ }^{\circ} \mathrm{C}$ under gentle stirring. The NGF dose was selected based on an earlier study showing that NGF significantly enhanced SCI repair at this concentration [24].

Lysozyme (lys) (Sigma-Aldrich) has a molecular weight and charge similar to those of NGF [25] and is less costly. We used lysozyme to evaluate the in vitro release kinetics of NGF $[26,27]$. In order to facilitate detection, the lysozyme was conjugated with fluorescein isothiocyanate (FITC) (Sigma-Aldrich) by combining the two reagents in distilled water at a weight ratio of 5:95 with stirring for $8 \mathrm{~h}$ at $4{ }^{\circ} \mathrm{C}$; the solution was then dialyzed and freezedried. A mixed solution of mPEG-PLV-TA copolymer and FITC-labeled lysozyme was transferred to cylindrical vials with a diameter of $16 \mathrm{~mm}$ that were placed in a water bath at $37^{\circ} \mathrm{C}$ until a hydrogel was formed. A $3.0 \mathrm{~mL}$ volume of PBS without or with $2.0 \mathrm{mg} / \mathrm{mL}$ elastase was slowly added to the vials, which was placed in shaking incubator at $37{ }^{\circ} \mathrm{C}$ and $70 \mathrm{rpm}$. PBS was collected at predetermined time points and fresh buffer was added to the samples. The cumulative release of lysozyme released into PBS was determined by measuring the fluorescence intensity of FITC with a microplate reader (Infinite M200; Tecan, Männedorf, Switzerland); the excitation wavelength was fixed at $495 \mathrm{~nm}$ and the emission spectrum was from 510 to $530 \mathrm{~nm}$.

\section{Assessment of axon growth in vitro}

PC-12 cells (purchased from BeNa Culture Collection) were grown in Dulbecco's modified Eagle's medium (DMEM supplemented with 10\% heat-inactivated horse serum and $5 \%$ fetal bovine serum (both from Gibco) in a humidified incubator $\left(37{ }^{\circ} \mathrm{C}, 5 \% \mathrm{CO}_{2}\right)$, and passaged every other day using $0.25 \%$ trypsin at $1: 2$ dilution. The cells were seeded on sterilized electroactive hydrogel (doped with $\mathrm{HCl}$ ) coated onto a coverslip with a diameter of $14 \mathrm{~mm}$ and treated with poly-L-Lysine at a density of $5 \times 10^{4}$ cells/well. ES was delivered with a waveform Generator (model DG1022U; Rigol, Beijing, China) and the signal was displayed and verified on a digital oscilloscope (model DS1102E; Rigol). A square wave with a frequency of $1 \mathrm{~Hz}, 5 \%$ duty cycle, and electrical potential of $0.1 \mathrm{~V}$ was used for stimulation. It's a cathode stimulation and the pulse peak is alternative current (AC). The ES was performed directly on the surface of the electroactive hydrogel via two microwire platinum electrodes (diameter of $0.5 \mathrm{~mm}$ ) for $1 \mathrm{~h}$ every day. After culturing for 3 days, the cells were fixed with $4 \%$ paraformaldehyde at room temperature and stained with $2 \%$ FITC in DMSO solution for $10 \mathrm{~min}$, then washed three times with 
PBS. Neurite morphology was assessed by CLSM; neurite length from the cell body to the most distal tip was measured using ImageJ software (National Institutes of Health, Bethesda, MD, USA).

\section{NSC culture and differentiation}

Newborn Sprague-Dawley rat pups were soaked in $75 \%$ ethanol for $0.5 \mathrm{~h}$ with only the head exposed, and the $\mathrm{SC}$ was removed with sterile forceps on a clean benchtop. The tissue was washed three times with prechilled D-Hank's solution and quickly transferred to a Petri dish and cut into small pieces using eye scissors that were transferred to a centrifuge tube with a sterile pipette. The medium containing the $\mathrm{SC}$ was triturated at a frequency of 10-12 times/min until there was no tissue obstruction and then centrifuged at $1000 \mathrm{rpm}$ for $5 \mathrm{~min}$. The supernatant was removed and sequentially passed through 200- and 500-mesh sieves to remove impurities. NSCs were seeded in a Petri dish at a density of $1 \times 10^{6}$ cells/ $\mathrm{mL}$ in serum-free medium containing DMEM/F12, $2 \%$ B27, $1 \%$ penicillin, $20 \mu \mathrm{g} / \mathrm{L}$ basic fibroblast growth factor (bFGF), and $20 \mu \mathrm{g} / \mathrm{L}$ epidermal growth factor (EGF) (all from Gibco), and cultured in an incubator at $37^{\circ} \mathrm{C}$ and $5 \% \mathrm{CO}_{2}$.

NSCs were inoculated in culture plates on the following substrates: slide (control), hydrogel plus ES (Gel+ES), hydrogel plus NGF (Gel + NGF), and hydrogel plus NGF and ES (Gel+NGF+ES). ES parameters are described in "NSC culture and differentiation" section.
Immunofluorescence labeling with nestin, class III beta tubulin (Tuj1), and glial fibrillary acidic protein (GFAP) antibodies was performed on days 1 and 7. Images of three random fields were acquired with an inverted microscope (Axio Vert. A1; Leica, Wetzlar, Germany).

\section{Surgical procedures and treatment of rats}

Sprague-Dawley rats were anesthetized with $2 \%$ isoflurane in oxygen and the SC was exposed with T10 as the center; the right $\mathrm{SC}$ was removed with the posterior midline of the SC as the boundary, forming a $2-\mathrm{mm}$ rectangular defect into which the hydrogels were implanted. Medical gelatin sponge was placed bilaterally in the paravertebral muscular space to absorb bleeding and prevent postoperative adhesion between the connective tissue and dura mater. The muscles were repositioned and sutured and the skin was stapled. To prevent postoperative infection, all rats were intramuscularly injected once daily with ampicillin $(150 \mathrm{mg} / \mathrm{kg})$ for 7 days, and the bladder was manually squeezed twice daily until the micturition reflex was restored.

Transcutaneous ES treatment was performed as follows. Rats were anesthetized with $2 \%$ isoflurane in oxygen and placed in a prone position. ES was delivered using a stimulator (model RM6240E; Chengdu Instrument Factory, Chengdu, China) through the skin of rats using an electrode needle. ES (square wave, $10 \mathrm{~Hz}, 3 \mathrm{~mA}$ ) was performed seven times ( $30 \mathrm{~min}$ each time) once daily starting on the first postoperative day. The positive

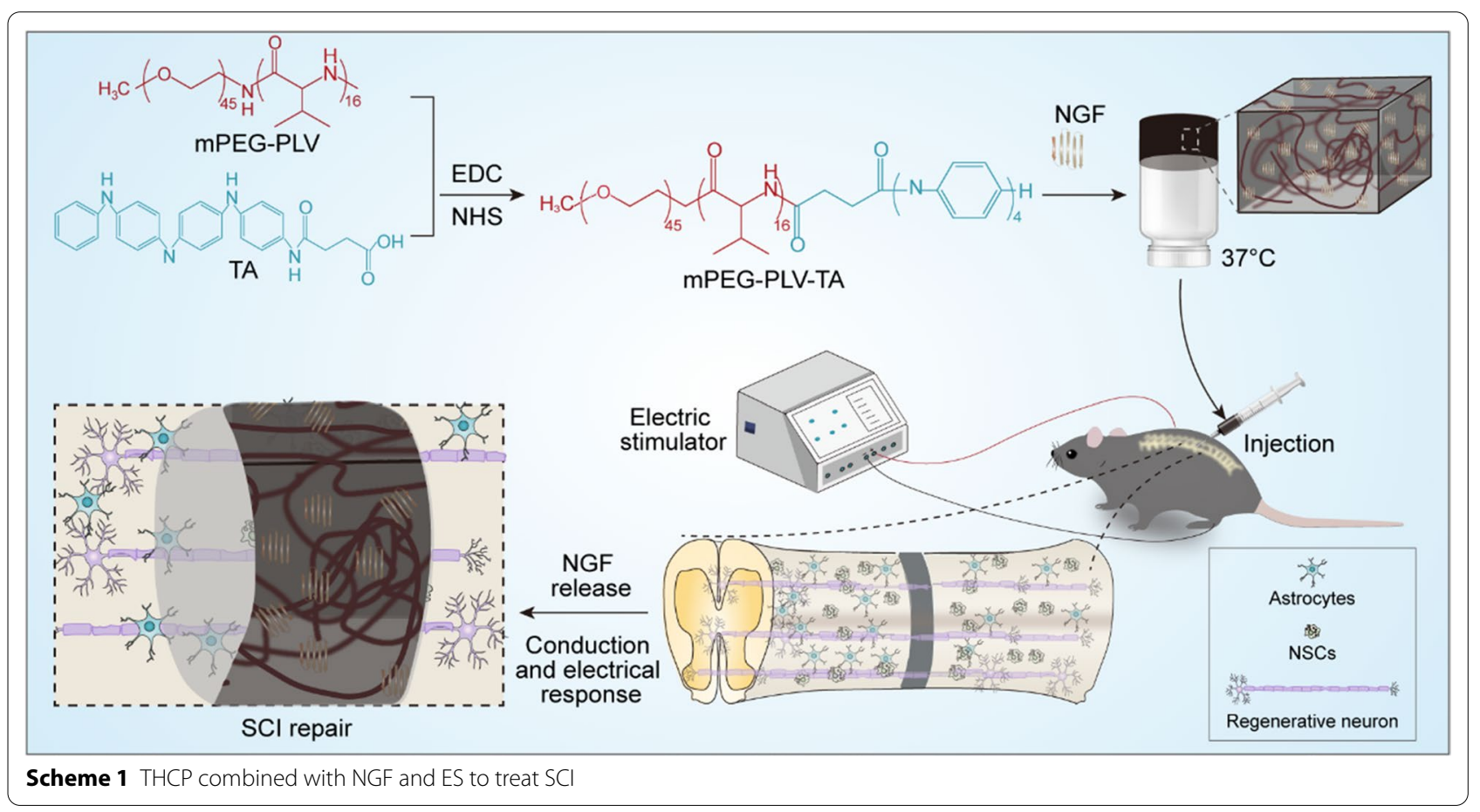




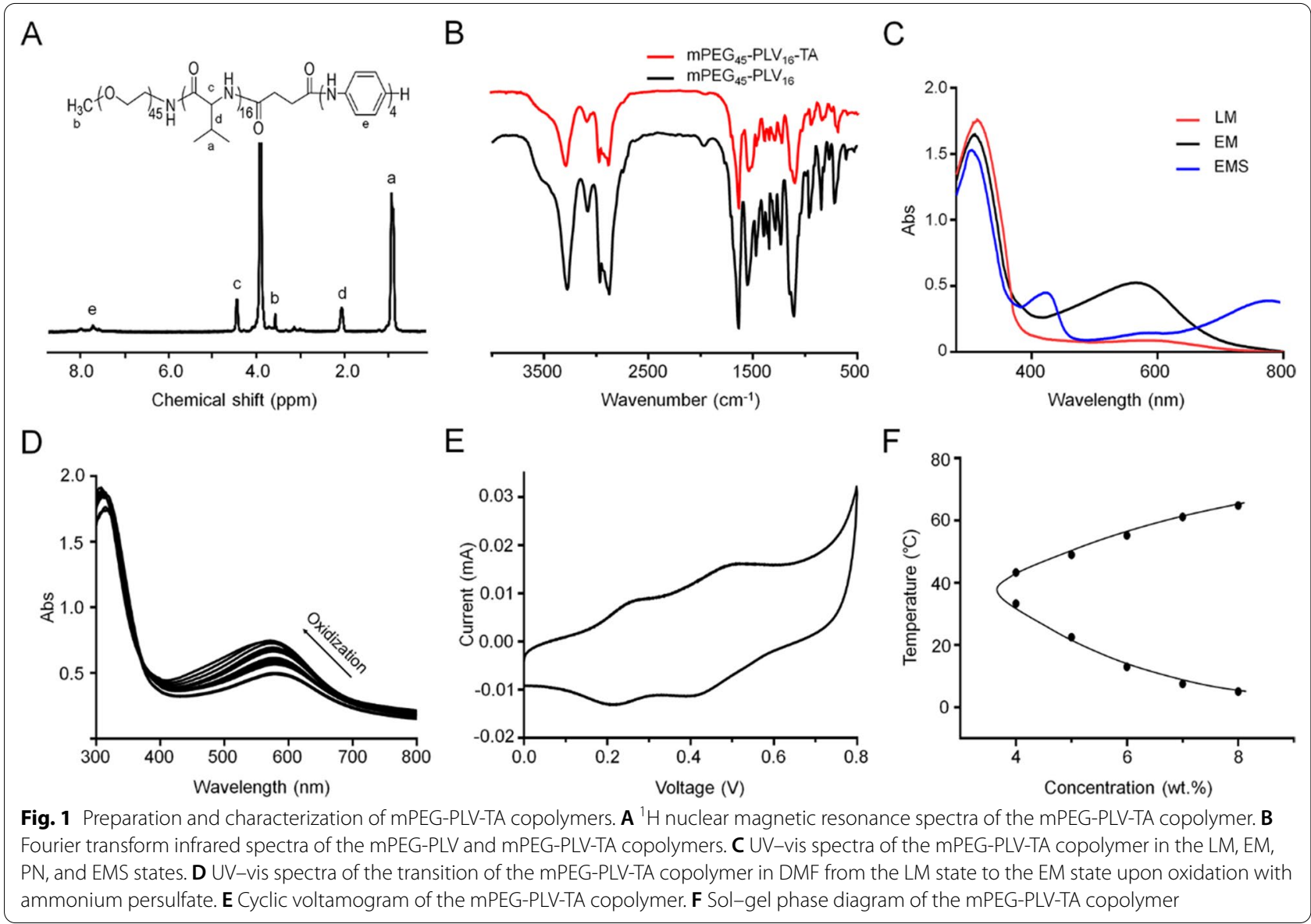

electrode was placed on the skin approximately $2 \mathrm{~cm}$ to the left of the midline at the posterior spinous process of T9, and the negative electrode was placed on the skin approximately $5 \mathrm{~mm}$ below the right knee joint and fibula head (Scheme 1).

\section{Results and discussion}

\section{Characterization of mPEG-PLV-TA copolymer}

The electroactive copolymer was synthesized by condensation crosslinking of mPEG-PLV and CTA. To confirm the structure of the electroactive copolymer, we tested ${ }^{1} \mathrm{H}$-nuclear magnetic resonance and Fourier transform infrared spectroscopy. All peaks in the copolymer were clearly assigned (Fig. 1A), demonstrating successful synthesis. Typical CTA absorption peaks were observed at 1603 and $1508 \mathrm{~cm}^{-1}$ (Fig. 1B) which corresponded to the stretching vibration of quinone and the benzenoid unit in CTA chain, which indicated that CTA was successfully grafted to mPEG-PLV.

Ultraviolet-visible light (UV-vis) absorption spectra of different oxidation states of the electroactive copolymer are shown in Fig. 1C. There were three oxidation states-i.e., pernigraniline (PNA), emeraldine salt (EMS) and leucoemeraldine (LM) when the copolymer was gradually oxidized, the benzenoid unit was replaced by a benzene ring. In the LM state, the only one absorption peak showed at $310 \mathrm{~nm}$ can be related to the $\pi-\pi^{*}$ transition of the benzenoid unit. In the EmS state, this absorption peak showed a marked blue shift and a new peak appeared at $575 \mathrm{~nm}$ corresponding to the excitonic transition of $\pi-\pi^{*}$ from benzenoid to the quinone unit [28]. When the copolymer in the EMS state was doped with $\mathrm{HCl}(1 \mathrm{M})$, new characteristic absorption peaks appeared at $430 \mathrm{~nm}$ and $>800 \mathrm{~nm}$, reflecting the formation of the EMS state and demonstrating the conductivity of the copolymer after doping [29]. Figure 1D showed the UV-vis spectrum of the gradual oxidation of the mPEGPLV-TA electroactive copolymer. When ammonium persulfate was gradually added to the DMF solution of the electroactive copolymer, the intensity of the absorption peak at $575 \mathrm{~nm}$ gradually increased; after reaching a maximum value, the intensity gradually diminished and showed a blue shift as the degree of oxidation increased.

This redox process was also be observed in the currentvoltage curve of the copolymer (Fig. 1E). There are two pairs of redox peaks on the curve, the first pair of more 
obvious reversible oxidation/reduction peaks, the average peak potential $\mathrm{E}_{1 / 2}=\left(\mathrm{E}_{\mathrm{pa}}+\mathrm{E}_{\mathrm{pc}}\right) / 2$ is $0.25 \mathrm{~V}$, the redox peak corresponds to the reduced state TA and the middle The oxidation-reduction relationship of the oxidation state TA; when the terminal amino group of the aniline tetramer forms an amide bond, it hinders the delocalization ability of the terminal amino group, resulting in the terminal amino group being unable to oxidize to form a quinone ring, so the second pair of redox peaks (corresponding to The redox relationship between the intermediate oxidation state TA and the high oxidation state TA) is not obvious compared to the first pair of redox peaks. The peaks may be due to the presence of part of free TA due to the rupture of the copolymer chains in the acid electrolyte.

From the results of ultraviolet spectrum and cyclic voltammetry spectrum, it can be seen that the aniline tetramer segment in the copolymer maintains good electrical activity in the aqueous solution.

\section{Gelation ability and internal structure}

Different concentrations of copolymer were dissolved in PBS at $4{ }^{\circ} \mathrm{C}$ to obtain homogeneous solutions. The temperature was gradually increased and changes in the state of the solution were examined. As the copolymer concentration increased from 4.0 to $8.0 \mathrm{wt} \%$, a stable gel was formed while the temperature of the sol-gel transition decreased from 33.3 to $5.0{ }^{\circ} \mathrm{C}$ (Fig. 1F). Considering the issues of injectability and gelation time during implantation, we selected the $6.0 \mathrm{wt} \%$ copolymer solution to prepare electroactive hydrogels for animal experiments. To determine whether the internal structure of the hydrogel was suitable for SC regeneration, we examined the ultrastructure by SEM. The hydrogel had uniform pores with a diameter of 30-70 $\mu \mathrm{m}$ (Fig. 2A), which can serve as channels for tissue fluid, exchange of metabolic substances, drug release, and axon growth.

\section{NGF release and hydrogel degradation}

Long-term nutrient deficiency after SCI impedes the speed and ultimate extent of tissue repair; this problem can potentially be overcome using a scaffold loaded with nutrients, and we therefore investigated whether the hydrogel can efficiently release NGF, which was substituted with lysozyme in this experiment. We loaded $20 \mathrm{mg} / \mathrm{mL}$ lysozyme into the electroactive hydrogel and observed the release kinetics [25]. Lysozyme encapsulated in the hydrogel showed burst release $(48.28 \% \pm 2.01 \%)$ in the first 4 days (Fig. $2 B$ ), which may have been due to its leaching out of the hydrogel with water. To simulate the release of lysozyme in the body

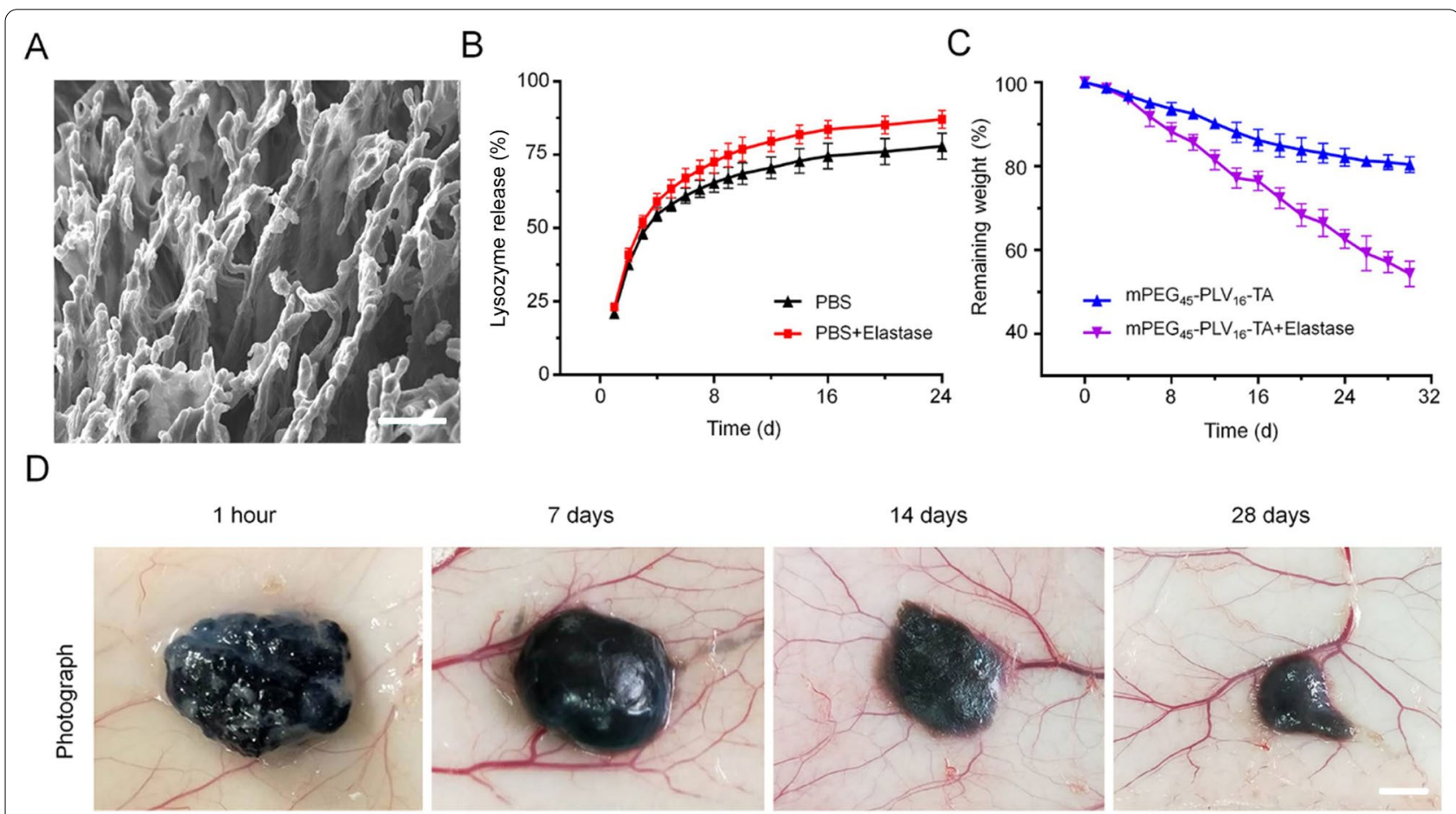

Fig. 2 Characterization of the electroactive hydrogel containing growth factors. A Microstructure observed by SEM. Scale bar, $50 \mu \mathrm{m}$. B Release kinetics of NGF in the electroactive hydrogel in PBS without or with elastase. $\mathbf{C}$ In vitro degradation profiles of the hydrogel in PBS without or with elastase. D Biodegradation of the hydrogel and local inflammation in vivo. Scale bar $=200 \mu \mathrm{m}$ and $50 \mathrm{~mm}$. Data are shown as mean \pm SD $(n=3)$ 
with hydrogel degradation, elastase $(2 \mathrm{mg} / \mathrm{L})$ was added to PBS and release kinetics were monitored [30]. After adding elastase, about $87.02 \% \pm 3.05 \%$ of the lysozyme was released from the hydrogel within 24 days, suggesting that the hydrogel can release loaded NGF in vivo over a sufficiently long period of time to allow nerve cell growth after SCI.

We evaluated the in vitro degradation of the hydrogel using samples in PBS alone or PBS containing elastase. Degradation was accelerated in the presence of elastase, with a hydrogel mass loss of $>80.3 \% \pm 1.86 \%$ within 30 days (Fig. 2C). These results demonstrate that the hydrogel is degraded at a moderate rate, which can benefit long-term tissue repair.

To further assess the degradation process and biocompatibility, the hydrogel was implanted under the skin of Sprague-Dawley rats. The hydrogel slowly degraded over a period of 4 weeks at a slightly faster rate than in vitro (Fig. 2D). We performed H\&E staining of the skin contacting the hydrogel obtained at different time points and found that acute inflammation occurred after the hydrogel was injected and was most prominent on day 7 . Over time, the inflammatory response gradually declined and there was no inflammation on day 28 (Additional file 1: Figure S1).

\section{Biocompatibility and cytotoxicity assessment in vitro}

To evaluate the in vitro cytotoxicity of the electroactive hydrogel, we carried out live-dead cell and MTT assays. PC12 cells were cocultured with hydrogel in mixed calcein-AM and PI dye solution; after 5 days, the cells were proliferating with no evidence of cell death (Fig. 3A). In the MTT assay, when the concentration of the hydrogel suspension increased from 0 to $500 \mu \mathrm{g} / \mathrm{mL}$, cell viability was in the range of $97.38 \% \pm 6.11 \%$ to $100 \% \pm 3.12 \%$ after $24 \mathrm{~h}$ (Fig. $3 \mathrm{C}$ ) and $90.40 \% \pm 1.22 \%$ to $100 \% \pm 3.48 \%$ after

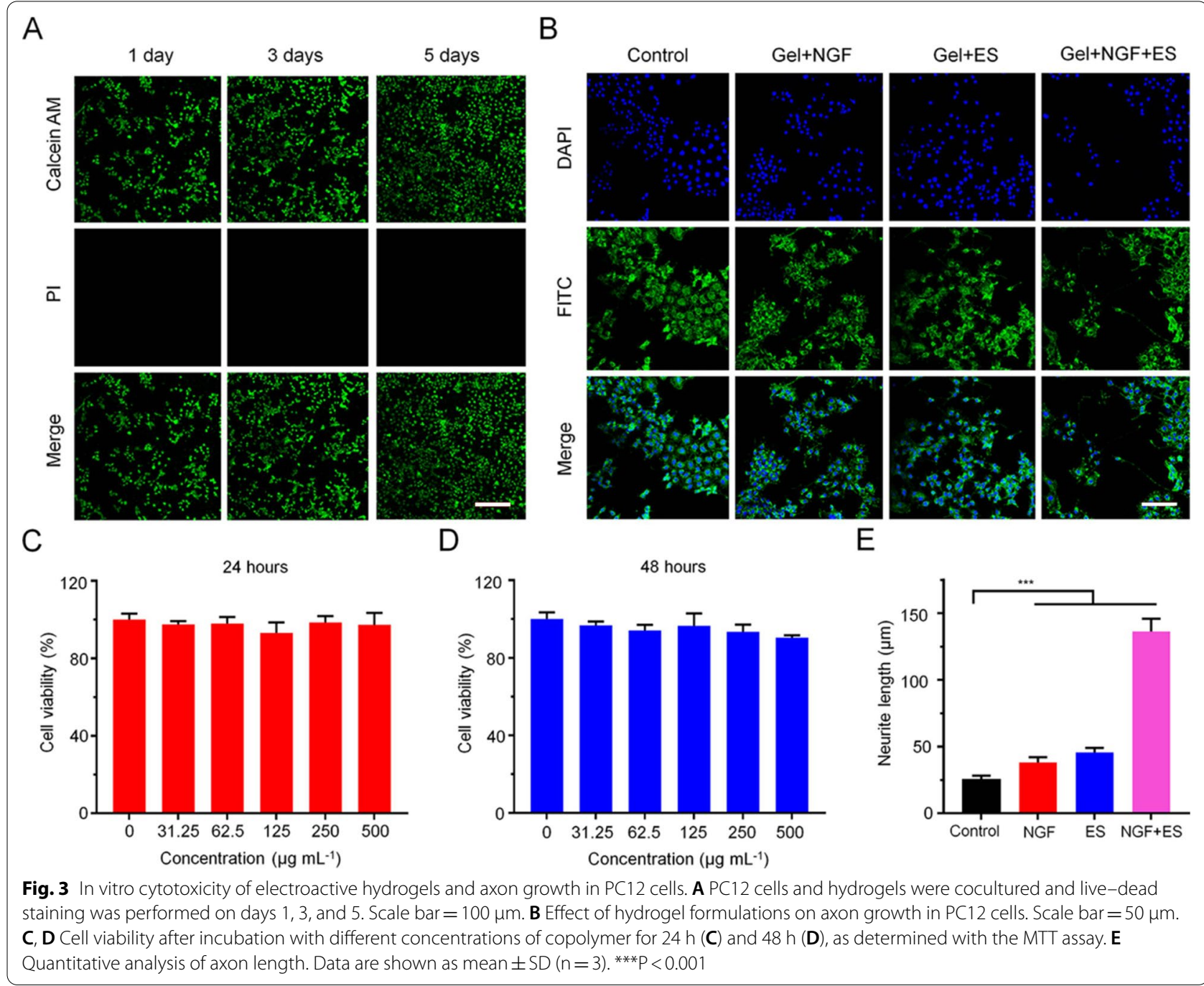


$48 \mathrm{~h}$ (Fig. 3D). Thus, the electroactive hydrogel has excellent biocompatibility and can be safely used for tissue repair.

\section{Axon growth and NSC differentiation in vitro}

CPs combined with ES can stimulate axon growth to promote nerve repair [31-33]. To investigate whether it can perform this function, the electroactive hydrogel was cocultured with PC12 cells and the length of axons emerging from the cells was analyzed [34]. In the
Gel + NGF and Gel + ES groups, only a few cells showed axon-like protrusions; in contrast, most cells in the Gel $+\mathrm{NGF}+\mathrm{ES}$ showed neurite outgrowth (Fig. 3B). The average neurite length in the Gel + NGF + ES group was $136.30 \mu \mathrm{m}$, which was significantly longer than that in the control $(25.48 \mu \mathrm{m}), \mathrm{Gel}+\mathrm{NGF}(38.64 \mu \mathrm{m})$, and Gel+ES $(45.12 \mu \mathrm{m})$ groups (Fig. 3E). These results demonstrate that while the hydrogel by itself has limited ability to stimulate axon growth in nerve cells, the effect can be enhanced by ES and NGF.

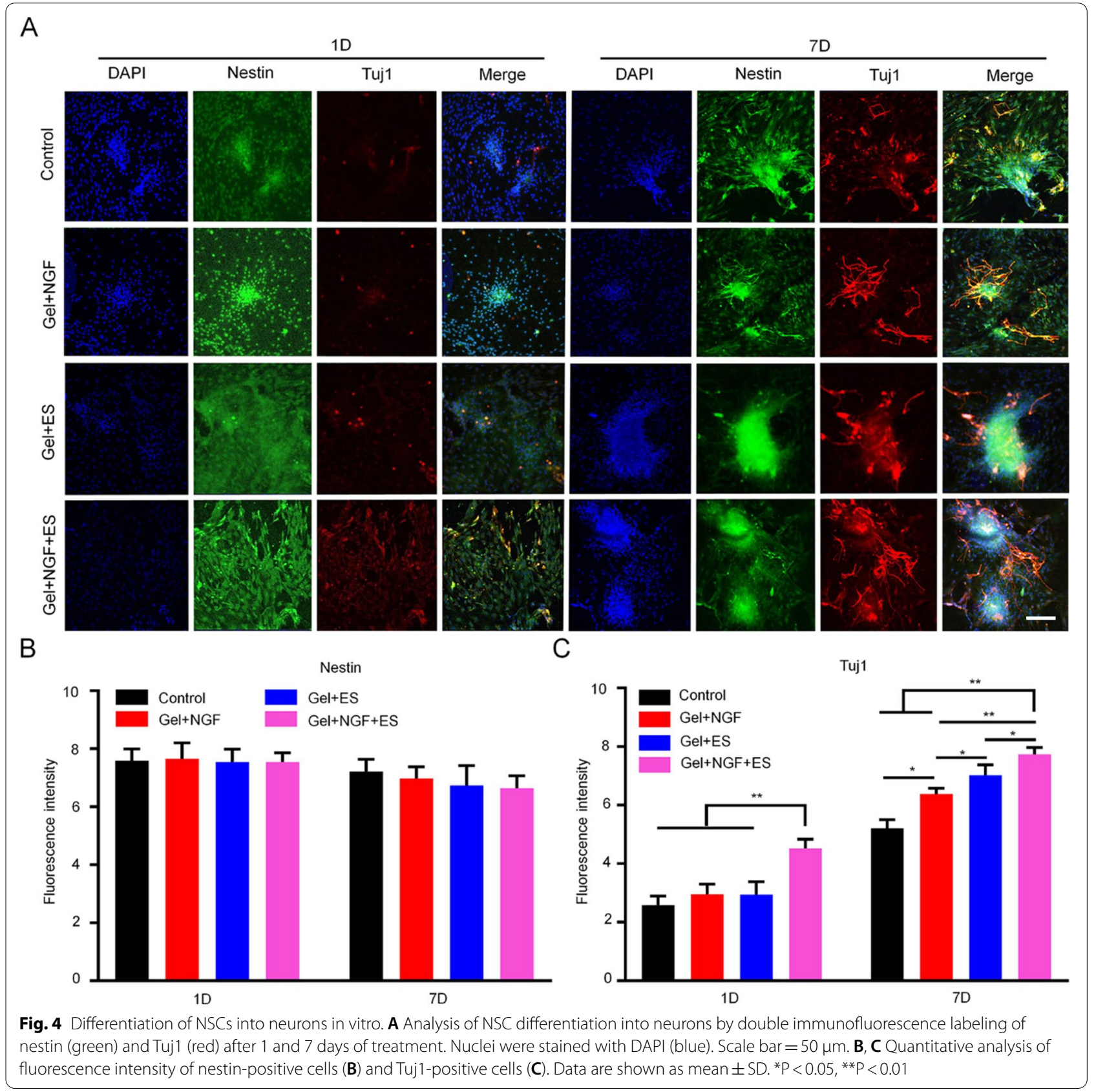




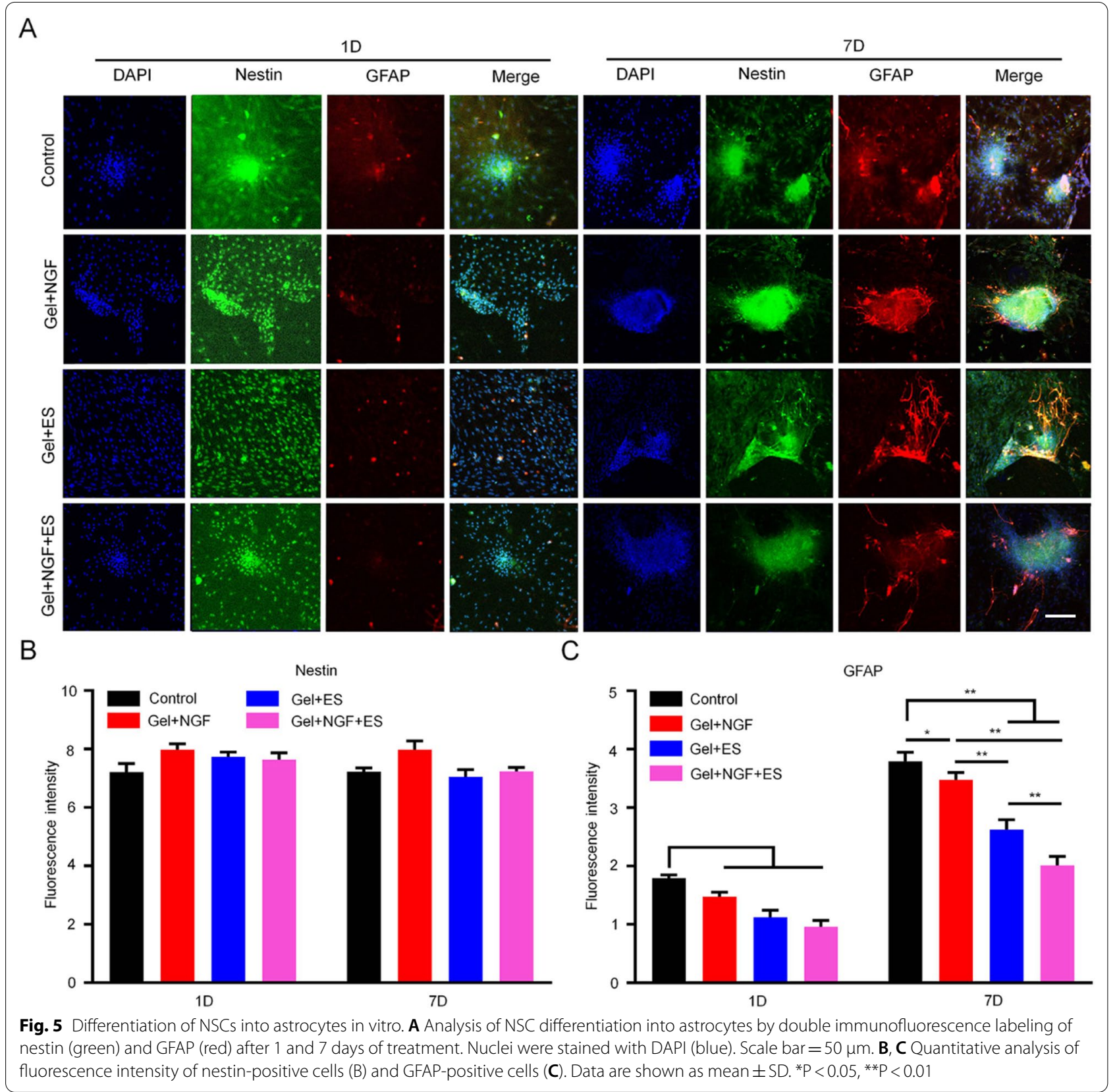

In addition to promoting axon growth, replacing dead neurons in the SC is an important strategy for restoring motor function. The softer hydrogel helps neural stem cells differentiate into neurons [35]. To verify whether our hydrogel can promote a large-scale differentiation of NSCs into neurons, NSCs were cocultured with the hydrogel and immunolabeling was performed to assess their differentiation status after 1 and 7 days. We found that the hydrogel induced the differentiation of NSCs into neurons and that the effect was potentiated by ES. This was accompanied by changes in cell morphology: neurites of a single neuron extended in all directions, forming an extensive network with other neurons (Fig. 4A). During this process, there were no changes in the expression level of nestin, a marker of NSCs, in any treatment groups (Figs. 4B and 5B). However, there was a significant increase in Tuj1 expression in all groups from day 1 to 7; the average fluorescence intensity on day 7 was 8.73 in the Gel + NGF + ES group, which was significantly higher than that in the control (5.21), Gel+NGF (6.37), and Gel+ES (7.02) groups (Fig. 4C). In contrast, the hydrogel had an inhibitory effect on NSC differentiation 


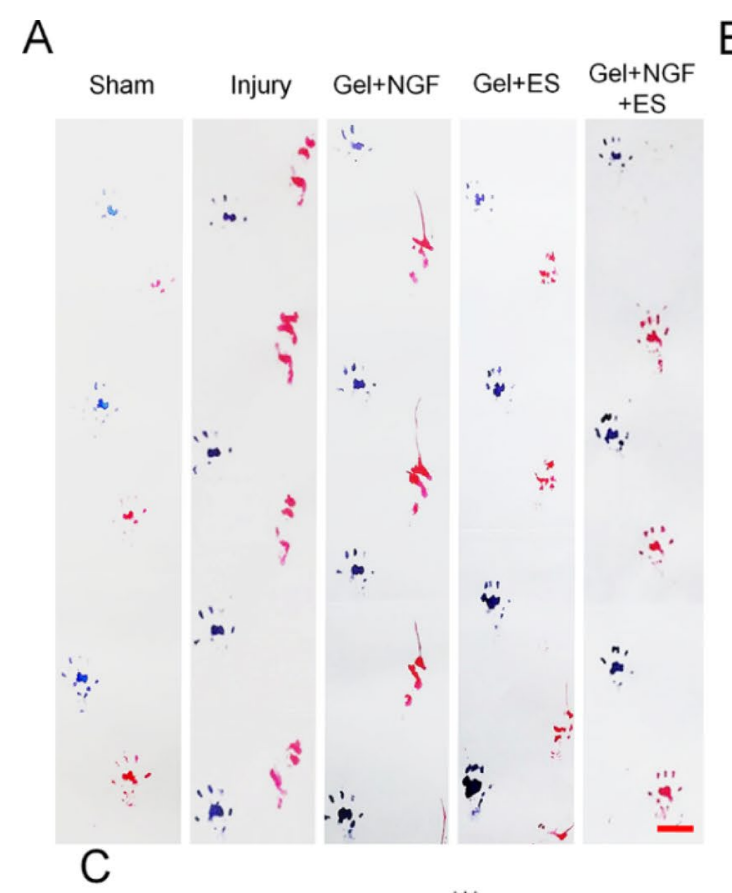

B

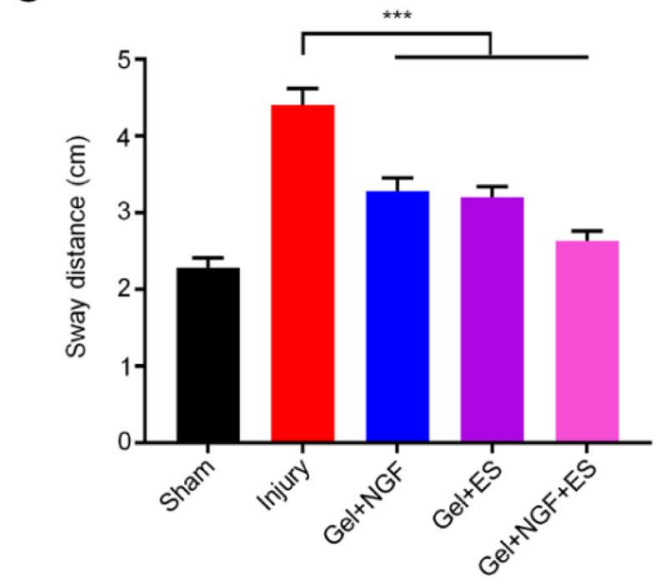

$\mathrm{E}$
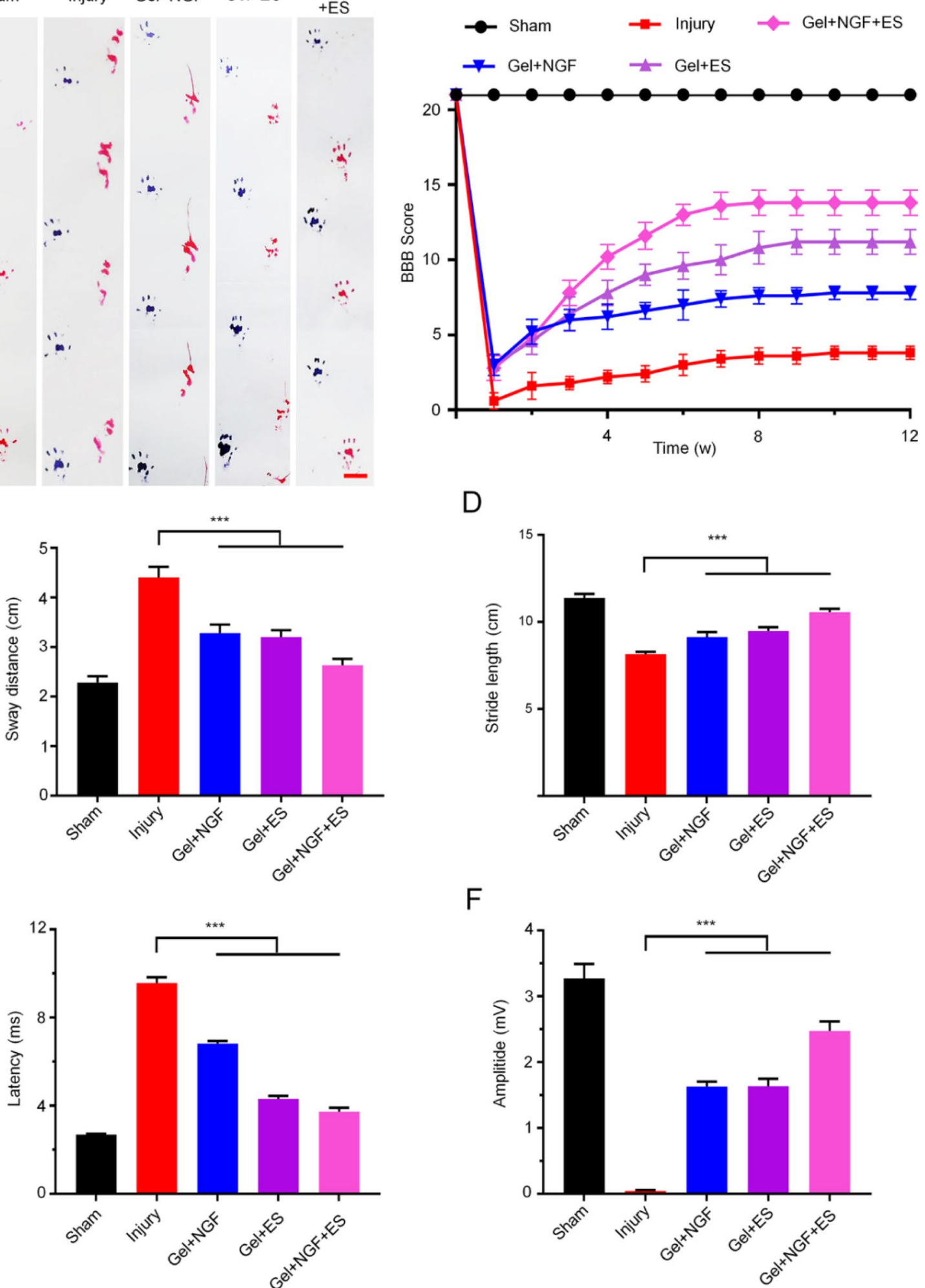

D

$\mathrm{F}$
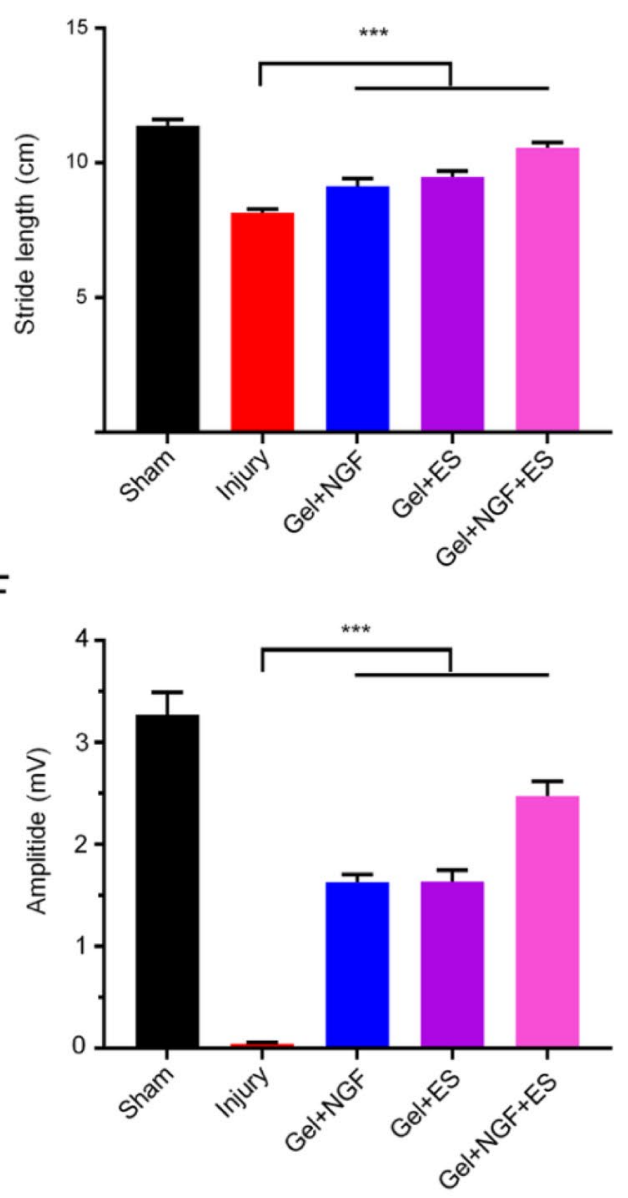

Fig. 6 Functional recovery post SCl. A Representative footprint patterns of different groups at 12 weeks after SCl. Scale bar $=2.5 \mathrm{~cm}$. B BBB score of rats at 12 weeks after $\mathrm{SCl}$. (C, D) Semiquantitative analysis of stride length $(\mathbf{C})$ and sway distance (D) in the footprint test. E, $\mathbf{F}$ MEP latency (E) and amplitude $(\mathbf{F})$. Data are shown as mean $\pm S D(n=3) .{ }^{* *} \mathrm{P}<0.001$ 
into astrocytes (Fig. 5A): the average fluorescence intensity of GFAP was lower in the Gel+NGF+ES group (4.01) on day 7 than in the control (7.58), Gel + NGF (6.95), and Gel+ES (5.24) groups (Fig. 5C). These results suggest that the hydrogel inhibits astrocyte proliferation and may prevent the formation of glial scars.

\section{Recovery of motor function and nerve conduction}

The restoration of motor function is the most important index for gauging SC repair. For the purpose of investigate the ability of the hydrogel to promote functional recovery, the footprint test was conducted and BBB score was evaluated in rats with SCI. At postoperative week 12 , the sham group showed a strong and stable normal gait in the footprint analysis, whereas injured rats showed a decreased stride length and increased sway distance with severe toe dragging (Fig. 6A). The treatment groups showed varying degrees of gait recovery: rats in the Gel+NGF+ES group had a stride length $(10.55 \pm 0.21 \mathrm{~cm})$ that was closer to that of the sham group $(11.38 \pm 0.22 \mathrm{~cm})$ than the Gel+NGF $(9.13 \pm 0.29 \mathrm{~cm})$ and $\mathrm{Gel}+\mathrm{ES}(9.48 \pm 0.21 \mathrm{~cm})$ groups, indicating that the recovery of motor function was greatest with the hydrogel loaded with NGF combined with ES (Fig. 6C). The same trend was observed for sway distance $(2.63 \pm 0.13 \mathrm{~cm}$ in the Gel+NGF + ES group vs $2.28 \pm 0.13 \mathrm{~cm}$ in the sham group) (Fig. 6D). Abnormal gait may be caused by decreased muscle tone, cerebellar dysfunction, impaired peripheral nerve function, or musculoskeletal abnormalities [36]. In this study, the degree of gait recovery was different, which could be due to the different degrees of regeneration and conduction of nerve cells in the gray and white matter, respectively; alternatively, inconsistent muscle tension caused by atrophic lower limb muscles may account for the observed differences.

To monitor the recovery of motor function of rats with SCI, we determined the BBB score in multiple different time points. The right hind limb of SCI model rats was paralyzed immediately after the operation, and the $\mathrm{BBB}$ score was close to 0 (Fig. $6 \mathrm{~B}$ ); even after 12 weeks, the score did not exceed 4 points, indicating that there was very little recovery after injury. In the treatment groups, the $\mathrm{BBB}$ score gradually increased over time; starting from week 4 after surgery, the fraction of Gel+NGF, $\mathrm{Gel}+\mathrm{ES}$, and Gel $+\mathrm{NGF}+\mathrm{ES}$ groups are significantly higher scores than the SCI model group and after 12 weeks, the BBB score of the Gel+NGF + ES group $(13.8 \pm 0.84)$ was higher than those of the other treatment groups.

We also evaluated the recovery of nerve conduction by measuring MEP. The amplitude of the MEP was reduced by SCI while the latency was increased, and there was no improvement in these parameters over time (Fig. 6E, F). After 12 weeks, the amplitude was increased in all treatment groups and the latency was shortened. The amplitude of the MEP was obviously higher in the Gel $+\mathrm{NGF}+\mathrm{ES}$ group $(2.47 \pm 0.14 \mathrm{mV})$ than in the Gel+NGF $(1.62 \pm 0.08 \mathrm{mV})$ and Gel+ES $(1.63 \pm 0.11 \mathrm{mV})$ groups. Similarly, the latency was shorter in the Gel+NGF+ES group $(3.73 \pm 0.18 \mathrm{~ms})$ than in the Gel+NGF $(6.81 \pm 0.13 \mathrm{~ms})$ and Gel+ES $(4.3 \pm 0.1 \mathrm{~ms})$ groups. Taken together, these results demonstrate that the NGF-loaded electroactive hydrogel combined with ES promoted the recovery of motor function in rats after SCI.

\section{Tissue repair in the SC}

We carried out histologic and ultrastructural analyses to confirm the repair of SC tissue. Rats were sacrificed 12 weeks post surgery and the SC was completely dissected. H\&E staining of tissue sections revealed that there was no new tissue growth in the SCI model group (Fig. 7A). However, the Gel $+\mathrm{NGF}+\mathrm{ES}$ group had smallest cavity area corresponding to the site of injury and more new tissue than the other treatment groups (Fig. 7B). A closer examination of SC ultrastructure by TEM indicated that compared to the sham group, SCI model rats had scar tissue hyperplasia and demyelination, with no obvious myelin sheath or axon regeneration, whereas myelinated axons were observed in the Gel + NGF, Gel + ES, and Gel+NGF + ES groups (Fig. 7C, D). These results demonstrate that the hydrogel with NGF and ES can promote nerve cell growth and $\mathrm{SC}$ tissue recovery.

\section{Differentiation of NSCs into neurons and inhibition of glial scar formation in vivo}

To determine whether the electroactive hydrogel loaded NGF combined with ES can facilitate the differentiation of NSCs into neurons in vivo, we performed double immunofluorescence labeling of SC tissue specimens with antibodies against nestin and Tuj1. There were no newborn neurons (Tuj1-positive cells) in the SCI model group, but they were observed in rats treated with Gel + NGF, Gel+ES, and Gel+NGF+ES (Fig. 8A). Notably, nestin and Tuj1 showed different degrees of expression and colocalization in areas of new tissue, suggesting that NSCs migrated from intact parts of the $\mathrm{SC}$ to the site of injury before differentiating into neurons. A semiquantitative analysis illustrated that the rate of neurogenesis in the Gel+ NGF + ES group was 1.2 and 3.1 times higher than that in Gel+NGF and Gel+ES groups, respectively (Fig. 8B, C). Although it 


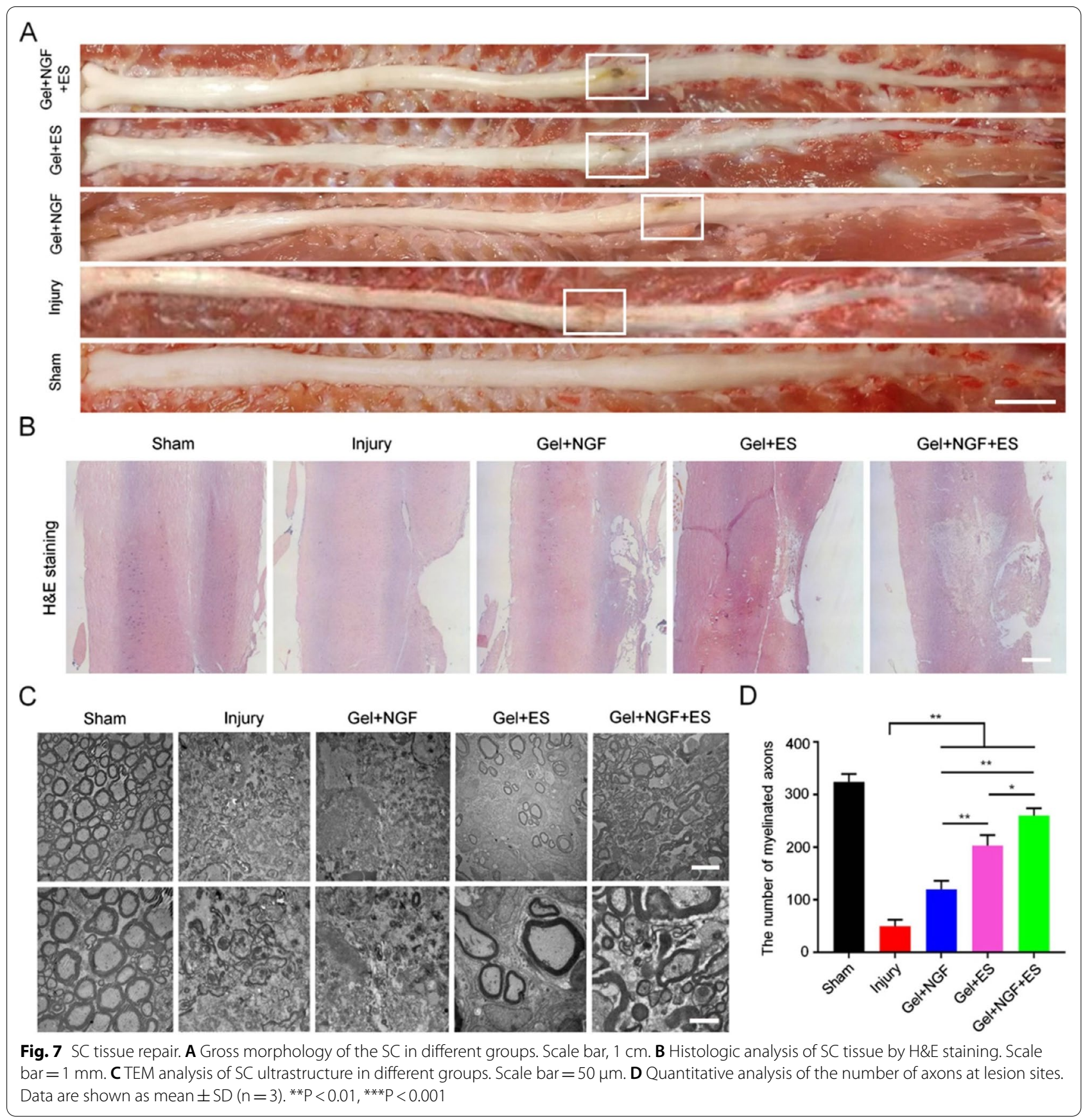

seems that the damage area of Gel + NGF + ES group is larger in terms of area, the damaged area is basically full of newly generated neuron cells, which is beneficial to the further repair of nerves. In the other treatment groups and injury groups, since the differentiation of neural stem cells into neurons was not stimulated, the cells in the damaged area were mainly other non-neuronal cells. This is not very helpful for the further repair of nerves.

Astrocytes are the dominant type of glial cell in the central nervous system and their continuous activation and hyperproliferation after SCI can lead to the formation of glial scars, which can prevent SC regeneration. Double immunolabeling of GFAP and Tuj1 in SC tissue sections proved that GFAP expression was higher in SCI model rats than in sham group (Fig. 9A, C) and 


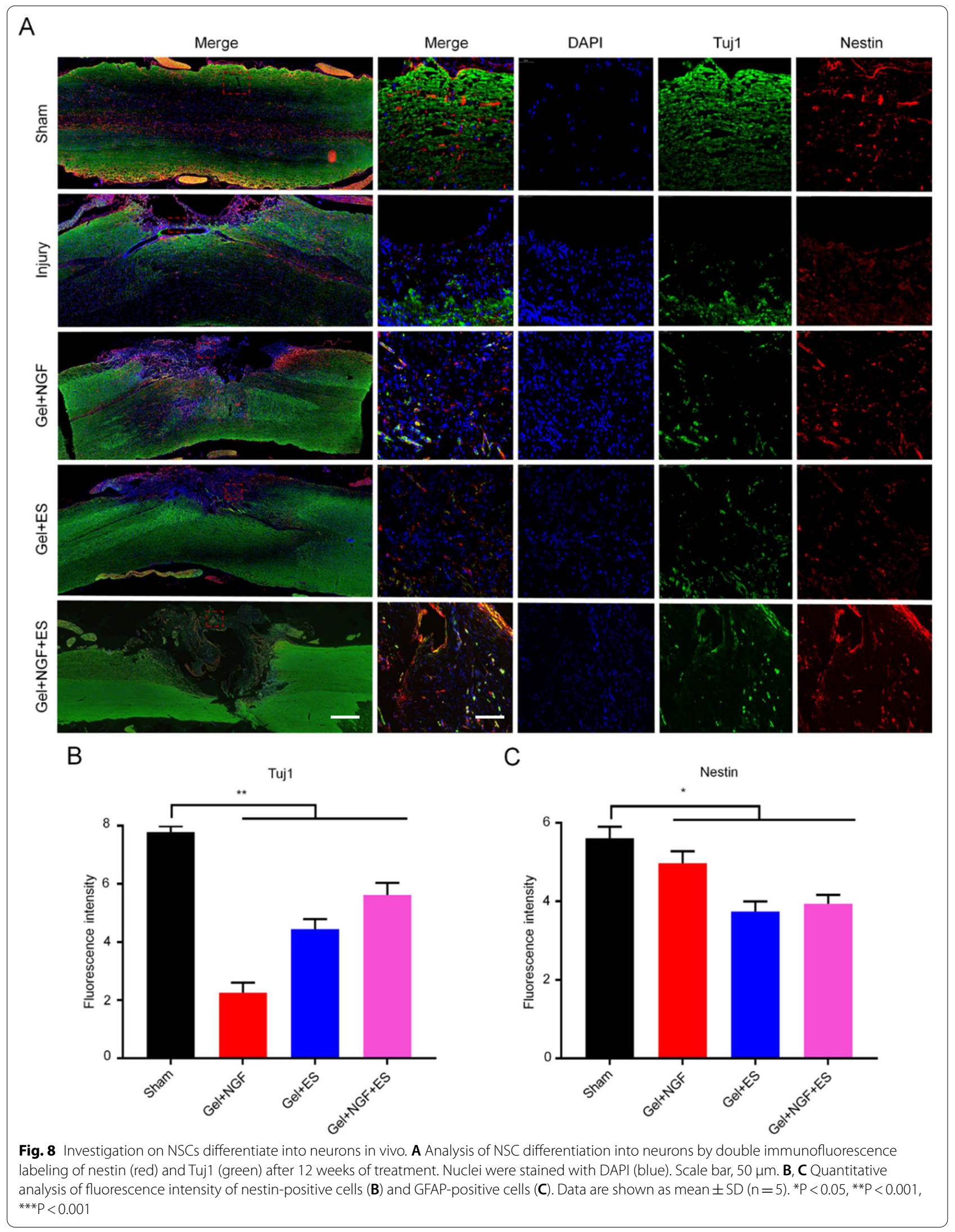




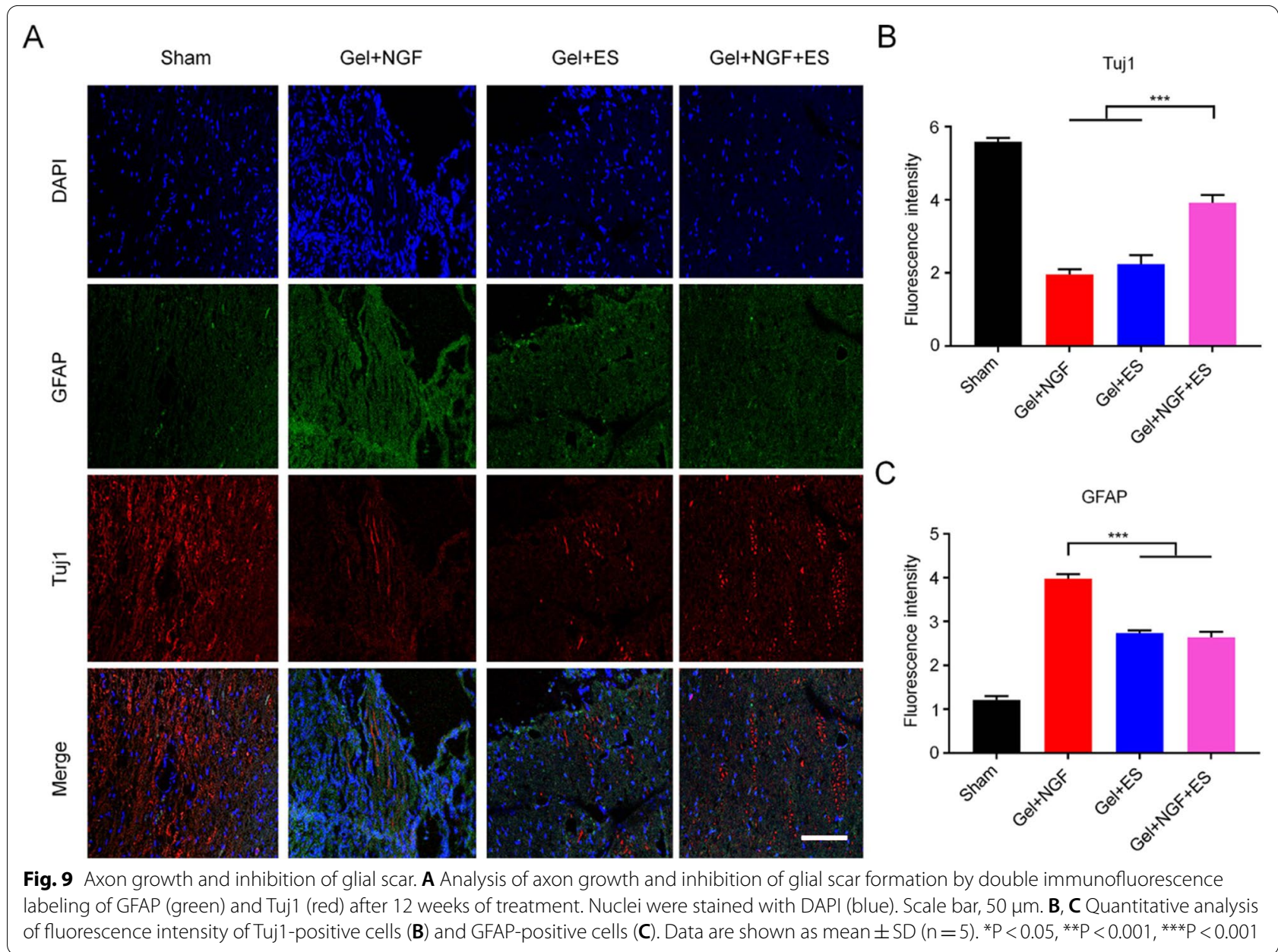

higher in the Gel+NGF group than in the Gel+ES and $\mathrm{Gel}+\mathrm{NGF}+\mathrm{ES}$ groups. This may be related to the fact that ES inhibits glial scar formation. In addition to being expressed by immature neurons, Tuj1 is also an axon marker. Tuj 1 expression was observed in all treatment groups, and the level in the Gel + NGF + ES group was significantly higher than that in the Gel + NGF and Gel + ES groups (Fig. 9A, B). Thus, the electroactive hydrogel loaded with NGF can promote axon regeneration in the injured SC, with ES enhancing this effect.

\section{Conclusion}

In summary, we prepared an electroactive hydrogel scaffold by grafting conductive TA onto poly $(\mathrm{L}-$ valine). The hydrogel was porous and showed good biocompatibility, biodegradability, and conductivity, and effectively stimulated SC tissue repair through continuous slow release of NGF and in response to external ES. These features induced the differentiation of NSCs into neurons in the injured SC while inhibiting the proliferation of astrocytes. Implantation of the hydrogel in SCI model rats stimulated endogenous neurogenesis and promoted the restoration of motor function. These results provide evidence that the electroactive hydrogel loaded with NGF and combined with ES has clinical potential for the treatment of SCI.

\section{Abbreviations}

BBB: Basso, Beattie, and Bresnahan; CLSM: Confocal laser scanning microscopy; CP: Conductive polymer; CTA: Carboxyl-capped aniline tetramer; DAPI: 4',6-Diamidino-2-phenylindole; DMEM: Dulbecco's modified Eagle's medium; DMF: N,N-Dimethylformamide; DMSO: Dimethyl sulfoxide; EDC: 1-Ethyl-3-(3dimethylaminopropyl)-carbodiimide; EMS: Emeraldine salt; ES: Electrical stimulation; FITC: Fluorescein isothiocyanate; GFAP: Glial fibrillary acidic protein; H\&E: Hematoxylin and eosin; LM: Leucoemeraldine; L-Val NCA: L-valineN-carboxylicanhydride; MEP: Motor evoked potential; mPEG: Poly(ethylene glycol) methyl ether; mPEG-PLV: Poly(ethylene glycol)-co-polyvaline; MTT: 
3-(4,5-Dimethylthiazol-2-yl)-2,5-diphenyltetrazolium bromide; NGF: Nerve growth factor; NHS: N-hydroxysuccinimide; NSC: Neural stem cell; PANI: Polyaniline; PBS: Phosphate-buffered saline; PI: Proidium iodide; PN: Pernigraniline state; SCI: Spinal cord injury; SEM: Scanning electron microscopy; TA: Tetraniline; TEM: Transmission electron microscopy; THF: Tetrahydrofuran; TPEH: Thermosensitive polymer electroactive hydrogel; Tuj1: Class III beta tubulin; UV-vis: Ultraviolet-visible light.

\section{Supplementary Information}

The online version contains supplementary material available at https://doi. org/10.1186/s12951-021-01031-y.

Additional file 1: Figure S1. Biocompatibility of electroactive hydrogel. Scale bar $=200 \mu \mathrm{m}$

\section{Acknowledgements}

This work was financially supported by the National Natural Science Foundation of China (Grant No. 82071391).

\section{Authors' contributions}

WL: Methodology, formal analysis, visualization. YL: Methodology, validation, formal analysis, investigation, resources, writing — original draft, visualization. CN: Methodology, Validation, formal analysis, investigation, resources, writing —original draft, visualization. WZ: Writing — review \& editing. QZ: Writing — review \& editing. HZ: Conceptualization, writing — review \& editing, supervision. CF: Conceptualization, writing — review \& editing, supervision, funding acquisition. All authors read and approved the final manuscript.

\section{Availability of data and materials}

All relevant data supporting the findings of this study are either included within the article and its additional files or available upon request from the corresponding author.

\section{Declarations}

\section{Competing interests}

The authors declare that they have no known competing financial interests or personal relationships that could have appeared to influence the work reported in this paper.

\section{Author details}

'Department of Spine Surgery, The First Hospital of Jilin University, 1 Xinmin Street, Changchun 130021, People's Republic of China. ${ }^{2}$ College of Chemistry, Jilin University, 2699 Qianjin Street, Changchun 130012, People's Republic of China. ${ }^{3}$ Department of Anesthesia, China-Japan Union Hospital of Jilin University, 126 Xiantai Street, Changchun 130033, People's Republic of China.

Received: 2 August 2021 Accepted: 8 September 2021

Published online: 23 September 2021

\section{References}

1. Silva NA, Sousa RA, Fraga JS, Fontes M, Leite-Almeida H, Cerqueira R, Almeida A, Sousa N, Reis RL, Salgado AJ. Benefits of spine stabilization with biodegradable scaffolds in spinal cord injured rats. Tissue Eng Part C Methods. 2013;19(2):101-8.

2. Li X, Xiao Z, Han J, Chen L, Xiao H, Ma F, Hou X, Li X, Sun J, Ding W, Zhao $Y$, Chen $B$, Dai J. Promotion of neuronal differentiation of neural progenitor cells by using EGFR antibody functionalized collagen scaffolds for spinal cord injury repair. Biomaterials. 2013;34(21):5107-16.

3. Wang YF, Zu JN, Li J, Chen C, Xi CY, Yan JL. Curcumin promotes the spinal cord repair via inhibition of glial scar formation and inflammation. Neurosci Lett. 2014;560:51-6.

4. Liu X, Miller AL 2nd, Park S, Waletzki BE, Zhou Z, Terzic A, Lu L. Functionalized carbon nanotube and graphene oxide embedded electrically conductive hydrogel synergistically stimulates nerve cell differentiation. ACS Appl Mater Interfaces. 2017;9(17):14677-90.

5. Wang XJ, Shu GF, Xu XL, Peng CH, Lu CY, Cheng XY, Luo XC, Li J, Qi $J$, Kang $X Q$, Jin FY, Chen MJ, Ying $X Y$, You J, Du YZ, Ji JS. Combinational protective therapy for spinal cord injury medicated by sialic acid-driven and polyethylene glycol based micelles. Biomaterials. 2019;217:119326.

6. Batty NJ, Torres-Espin A, Vavrek R, Raposo P, Fouad K. Single-session cortical electrical stimulation enhances the efficacy of rehabilitative motor training after spinal cord injury in rats. Exp Neurol. 2020;324:113136.

7. Calvert JS, Grahn PJ, Zhao KD, Lee KH. Emergence of epidural electrical stimulation to facilitate sensorimotor network functionality after spinal cord injury. Neuromodul Technol Neural Interface. 2019;22(3):244-52.

8. Pan S, Zhao Y, Qiao X, Qi Z, Fu C, Kong W, Liu Q, Yang X. PLGA porous scaffolds by polydopamine-assisted immobilization of NGF for spinal cord injury repair. Mater Res Expr. 2019;6(4):045024

9. Hu X, Li R, Wu Y, Li Y, Zhong X, Zhang G, Kang Y, Liu S, Xie L, Ye J, Xiao J. Thermosensitive heparin-poloxamer hydrogel encapsulated bFGF and NGF to treat spinal cord injury. J Cell Mol Med. 2020;24:8166-78.

10. Alastra G, Aloe L, Baldassarro VA, Calzà L, Cescatti M, Duskey JT, Focarete ML, Giacomini D, Giardino L, Giraldi V, Lorenzini L, Moretti M, Parmeggiani I, Sannia M, Tosi G. Nerve growth factor biodelivery: a limiting step in moving toward extensive clinical application? Front Neurosci. 2021;15:879.

11. Zhou L, Fan L, Yi X, Zhou Z, Liu C, Fu R, Dai C, Wang Z, Chen X, Yu P, Chen D, Tan G, Wang Q, Ning C. Soft conducting polymer hydrogels cross-linked and doped by tannic acid for spinal cord injury repair. ACS Nano. 2018:12(11):10957-67.

12. Zhang X, Li L, Ouyang J, Zhang L, Xue J, Zhang H, Tao W. Electroactive electrospun nanofibers for tissue engineering. Nano Today. 2021;39:101196.

13. Huang C, Fu C, Qi ZP, Guo WL, You D, Li R, Zhu Z. Localised delivery of quercetin by thermo-sensitive PLGA-PEG-PLGA hydrogels for the treatment of brachial plexus avulsion. Artif Cells Nanomed Biotechnol. 2020;48(1):1010-21.

14. Jiang L, Wang Y, Liu Z, Ma C, Yan H, Xu N, Gang F, Wang X, Zhao $L$, Sun $X$. Three-dimensional printing and injectable conductive hydrogels for tissue engineering application. Tissue Eng Part B Rev. 2019;25(5):398-411.

15. Amani $H$, Kazerooni $H$, Hassanpoor $H$, Akbarzadeh A, Pazoki-Toroudi $H$. Tailoring synthetic polymeric biomaterials towards nerve tissue engineering: a review. Artif Cells Nanomed Biotechnol. 2019;47(1):3524-39.

16. Huang Y, Kormakov S, He X, Gao X, Zheng X, Liu Y, Sun J, Wu D. Conductive polymer composites from renewable resources: an overview of preparation, properties, and applications. Polymers. 2019;11(2):187.

17. Sadeghi A, Moztarzadeh F, Aghazadeh Mohandesi J. Investigating the effect of chitosan on hydrophilicity and bioactivity of conductive electrospun composite scaffold for neural tissue engineering. Int J Biol Macromol. 2019;121:625-32.

18. Datta S, Das A, Sasmal P, Bhutoria S, Roy Chowdhury A, Datta P. Alginate-poly(amino acid) extrusion printed scaffolds for tissue engineering applications. Int J Polym Mater Polym Biomater. 2018;69(2):65-72.

19. Miyazaki M, Maeda T, Hirashima K, Kurokawa N, Nagahama K, Hotta A. PEG-based nanocomposite hydrogel: thermoresponsive sol-gel transition controlled by PLGA-PEG-PLGA molecular weight and solute concentration. Polymer. 2017;115:246-54.

20. Ouyang J, Ji XY, Zhang XC, Feng C, Tang ZM, Kong N, Xi A, Wang JQ, Sui XB, Deng L, Liu YN, Kim JS, Cao YH, Tao W. In situ sprayed NIRresponsive, analgesic black phosphorus-based gel for diabetic ulcer treatment. Proc Natl Acad Sci. 2020;117(46):28667-77.

21. Feng C, Ouyang J, Tang ZM, Kong N, Liu Y, Fu LY, Ji XY, Xie T, Farokhzad OC, Tao W. Germanene-based theranostic materials for surgical adjuvant treatment: inhibiting tumor recurrence and wound infection. Matter. 2020;3(1):127-44.

22. Ding JX, Shi FH, Xiao CS, Lin L, Chen L, He CL, Zhuang XL, Chen XS. One-step preparation of reduction-responsive poly(ethylene glycol)poly (amino acid)s nanogels as efficient intracellular drug delivery platforms. Polym Chem. 2011;2(12):2857-64.

23. Liu YD, Hu J, Zhuang XL, Zhang PBA, Chen XS, Wei Y, Wang XH. Preparation and characterization of biodegradable and electroactive polymer 
blend materials based on MPEG/tetraaniline and PLLA. Macromol Biosci. 2011;11(6):806-13.

24. Zhao YZ, Jiang X, Xiao J, Lin Q, Yu WZ, Tian FR, Mao KL, Yang W, Wong HL, Lu CT. Using NGF heparin-poloxamer thermosensitive hydrogels to enhance the nerve regeneration for spinal cord injury. Acta Biomater. 2016;29:71-80.

25. Song B, Song J, Zhang S, Anderson MA, Ao Y, Yang CY, Deming TJ, Sofroniew MV. Sustained local delivery of bioactive nerve growth factor in the central nervous system via tunable diblock copolypeptide hydrogel depots. Biomaterials. 2012;33(35):9105-16.

26. Stukel J, Thompson S, Simon L, Willits R. Polyethlyene glycol microgels to deliver bioactive nerve growth factor. J Biomed Mater Res Part A. 2015;103(2):604-13.

27. Jiang G, Woo BH, Kang F, Singh J, DeLuca PP. Assessment of protein release kinetics, stability and protein polymer interaction of lysozyme encapsulated poly (D, L-lactide-co-glycolide) microspheres. J Control Release. 2002;79(1-3):137-45.

28. Huang $L$, Hu J, Lang L, Wang $X$, Zhang $P$, Jing $X$, Wang $X$, Chen $X$, Lelkes $\mathrm{PI}$, Macdiarmid AG, Wei Y. Synthesis and characterization of electroactive and biodegradable ABA block copolymer of polylactide and aniline pentamer. Biomaterials. 2007;28(10):1741-51.

29. Huang $L$, Zhuang $X$, Hu J, Lang $L$, Zhang $P$, Wang $Y$, Chen $X$, Wei $Y$, Jing $X$. Synthesis of biodegradable and electroactive multiblock polylactide and aniline pentamer copolymer for tissue engineering applications. Biomacromol. 2008;9(3):850-8.

30. Zhang W, Ning C, Xu W, Hu H, Li M, Zhao G, Ding J, Chen X. Precisionguided long-acting analgesia by Gel-immobilized bupivacaine-loaded microsphere. Theranostics. 2018;8(12):3331.
31. Touwslager F, Willard N, Leeuw D. I-line lithography of poly-(3,4ethylenedioxythiophene) electrodes and application in all-polymer integrated circuits. Appl Phys Lett. 2002;81(24):4556-8.

32. Zhao H, Steiger A, Nohner M, Ye H. Specific intensity direct current (DC) electric field improves neural stem cell migration and enhances differentiation towards $\beta$ III-tubulin+ neurons. PLOS ONE. 2015;10(6):e0129625

33. Stewart E, Kobayashi NR, Higgins MJ, Quigley AF, Jamali S, Moulton SE, Kapsa RMI, Wallace GG, Crook JM. Electrical stimulation using conductive polymer polypyrrole promotes differentiation of human neural stem cells: a biocompatible platform for translational neural tissue engineering. Tissue Eng, Part C. 2015;21(4):385-93.

34. Hu J, Huang $L$, Zhuang $X$, Zhang $P$, Lang L, Chen $X$, Wei $Y$, Jing $X$. Electroactive aniline pentamer cross-linking chitosan for stimulation growth of electrically sensitive cells. Biomacromol. 2008;9(10):2637-44.

35. Kang PH, Schaffer DV, Kumar S. Angiomotin links ROCK and YAP signaling in mechanosensitive differentiation of neural stem cells. Mol Biol Cell. 2020;31(5):386-96.

36. Girirajan S, Patel N, Slager RE, Tokarz ME, Bucan M, Wiley JL, Elsea SH. How much is too much? Phenotypic consequences of Rai1 overexpression in mice. Eur J Hum Genet EJHG. 2008;16(8):941-54.

\section{Publisher's Note}

Springer Nature remains neutral with regard to jurisdictional claims in published maps and institutional affiliations.
Ready to submit your research? Choose BMC and benefit from:

- fast, convenient online submission

- thorough peer review by experienced researchers in your field

- rapid publication on acceptance

- support for research data, including large and complex data types

- gold Open Access which fosters wider collaboration and increased citations

- maximum visibility for your research: over $100 \mathrm{M}$ website views per year

At BMC, research is always in progress.

Learn more biomedcentral.com/submissions 